\title{
Diagnostic Value of the Hypomethylation of the WISP1 Promoter in Patients with Hepatocellular Carcinoma Associated with Hepatitis B Virus
}

\author{
La-Mei Chen, ${ }^{1}$ Lin Xiang, ${ }^{1}$ Wei-Juan Sun, ${ }^{1}$ Yu-Jia Zhai, ${ }^{1}$ Shuai Gao, ${ }^{1,2}$ \\ Yu-Chen Fan ${ }^{1,2,3}$ and Kai Wang ${ }^{1,2,3}$ \\ ${ }^{1}$ Department of Hepatology, Qilu Hospital of Shandong University, Jinan, Shandong, China \\ ${ }^{2}$ Institute of Hepatology, Shandong University, Jinan, Shandong, China \\ ${ }^{3}$ Shenzhen Research Institute of Shandong University, Shenzhen, Guangdong, China
}

Wnt1-inducible signaling pathway protein 1 (WISP1) regulates cell proliferation, differentiation, adhesion, migration and survival. Abnormal WISP1 expression is associated with the carcinogenesis of hepatocellular carcinoma (HCC). Aberrant DNA methylation is one of the major epigenetic alterations in HCC. However, the methylation status of the WISP1 promoter is still unclear. We therefore aimed to determine the methylation status of the WISP1 promoter and evaluate its clinical value in HCC. The study enrolled 251 participants, including 123 participants with HCC, 90 participants with chronic hepatitis $\mathrm{B}(\mathrm{CHB})$ and 38 healthy controls (HCs). WISP1 methylation status, mRNA levels and plasma soluble WISP1 were detected by methylation-specific polymerase chain reaction (MSP), quantitative real-time PCR (RT-qPCR) and enzyme-linked immunosorbent assay (ELISA), respectively. We found that the methylation frequency of WISP1 in patients with HCC was significantly lower than that in patients with $\mathrm{CHB}$ and $\mathrm{HCs}$, while the relative expression levels of WISP1 mRNA were markedly higher in patients with HCC than in patients with $\mathrm{CHB}$ and HCs. Furthermore, the plasma soluble WISP1 in patients with HCC was obviously lower than in that in patients with $\mathrm{CHB}$ and $\mathrm{HCs}$. Alpha-fetoprotein (AFP) is a widely recognized biomarker to diagnose HCC which lacks enough sensitivity and specificity. WISP1 promoter methylation status combined with AFP significantly improved the diagnostic ability in discriminating $\mathrm{HCC}$ from $\mathrm{CHB}$ compared with AFP or WISP1 methylation status alone. In conclusion, hypomethylation of the WISP1 gene promoter may serve as a noninvasive biomarker for detecting HBV-associated HCC.

Keywords: biomarker; DNA methylation; hepatocellular carcinoma; methylation-specific polymerase chain reaction; Wnt1-inducible signaling pathway protein 1

Tohoku J. Exp. Med., 2020 December, 252 (4), 297-307.

\section{Introduction}

Liver cancer is the sixth most commonly diagnosed cancer and the fourth leading cause of cancer death worldwide in 2018, with approximately 841,000 new cases and 782,000 deaths annually. Approximately $75 \%-85 \%$ of primary liver cancers are hepatocellular carcinoma (HCC). China is one of the most high-risk areas of HCC, and the key determinants of HCC in China are chronic infection with hepatitis B (HBV) and aflatoxin exposure (Lai et al. 2003; Bray et al. 2018; Ferlay et al. 2019). Although the diagnosis and management of HCC have improved, the mean survival of HCC patients is estimated to be between 6 and 20 months (Byam et al. 2013). At present, the diagnosis of HCC mainly depends on serum AFP levels and imaging, and there are limitations. The Asian Pacific Association for the Study of the Liver (APASL) HCC Guidelines no longer recommends AFP levels as a screening tool to monitor HCC because it lacks sufficient sensitivity and specificity (Omata et al. 2017; Luo et al. 2020). Some patients at an advanced stage of HCC are asymptomatic, leading to poor prognosis (Chonprasertsuk and Vilaichone 2017). Early detection is the only hope for effective and curative treatment of patients with HCC, and it emphasizes the criti-

Received August 11, 2020; revised and accepted November 4, 2020. Published online November 26, 2020; doi: 10.1620/tjem.252.297. Correspondence: Kai Wang, Department of Hepatology, Qilu Hospital of Shandong University and Institute of Hepatology, Shandong University, 107\# Wenhuaxi Road, Jinan, Shandong 250012, China. e-mail: wangdoc876@126.com or wangdoc2010@163.com

(C)2020 Tohoku University Medical Press. This is an open-access article distributed under the terms of the Creative Commons Attribution-NonCommercial-NoDerivatives 4.0 International License (CC-BY-NC-ND 4.0). Anyone may download, reuse, copy, reprint, or distribute the article without modifications or adaptations for non-profit purposes if they cite the original authors and source properly.

https://creativecommons.org/licenses/by-nc-nd/4.0/ 
cal role of screening strategies in the surveillance of highrisk patients (Ding et al. 2019). The gold standard for HCC diagnosis is liver biopsy; however, biopsy is an invasive test with its own set of risks. Therefore, new biomarkers for timely diagnosis and monitoring of HCC are urgently needed.

DNA methylation is a well-studied epigenetic marker in mammals, and it plays a vital role in genomic imprinting, chromatin architecture, and gene regulation (Jaenisch and Bird 2003; Baubec and Schübeler 2014; Kim and Costello 2017; Ginno et al. 2020). DNA methylation is considered a stable epigenetic marker, and methylation patterns vary in diseases such as cancer (Smith and Meissner 2013). During cancer initiation and progression, genome-wide and genespecific DNA methylation changes occur as a consequence of mutated or deregulated chromatin regulators. DNA methylation differences among different regions of a tumor reflect the history of cancer cells and their response to the tumor microenvironment (Bird 2002; Kim and Costello 2017). When DNA hypermethylation occurs in the gene promoter region, the gene might be silenced and inactivated. DNA hypomethylation may contribute to the generation of chromosomal instability, the reactivation of transposable elements or the loss of imprinting (Esteller 2007; Lambert et al. 2011). Therefore, DNA methylation status could be a useful molecular biomarker for cancer diagnosis and progression.

Wnt1-inducible signaling pathway protein 1 (WISP1) is a member of the connective tissue growth factor/cysteinrich 61/nephroblastoma overexpressed (CCN) family of secreted extracellular matrix (ECM)-associated signaling proteins. The WISPl gene is located on chromosome 8q24.1-8q24.3 (Pennica et al. 1998). WISP1 is involved in different physiological functions including cell proliferation, apoptosis, invasion, metastasis, embryonic development and tissue repair (Li et al. 2015). Aberrant WISP1 expression is associated with multiple solid human tumors and plays a pivotal role in tumorigenesis and progression (Liu et al. 2019). Studies have shown that WISP1 is linked to colon cancer, oral squamous cell carcinoma, gastric cancer, breast cancer, esophageal cancer, prostate cancer, hepatocellular carcinoma and so on (Nagai et al. 2011; Ono et al. 2013; Chiang et al. 2015; Gurbuz and ChiquetEhrismann 2015; Clausen et al. 2016; Wu et al. 2016; Yan et al. 2018; Loftus et al. 2020; Zhang et al. 2019). Clausen et al. (2016) noticed that WISP1 expression was regulated by DNA methylation and that WISP1 demethylation contributed to lymph node metastasis in patients with oral squamous cell carcinoma.

As far as we know, the DNA methylation status of the WISP1 gene during HCC development remains unknown. In our present study, methylation-specific PCR (MSP) was performed to detect the methylation status of WISP1 in peripheral blood mononuclear cells (PBMCs) in patients with HCC, patients with $\mathrm{CHB}$ and HCs. In addition, we used quantitative real-time polymerase chain reaction
(RT-qPCR) to evaluate WISP1 mRNA and enzyme-linked immunosorbent assay (ELISA) to determine WISP1 protein in plasma. Combined with clinicopathological features, we assessed the diagnostic and prognostic value of WISPI methylation status as a noninvasive biomarker for HBVassociated HCC. The main sample of our study was PBMCs. The reasons why we chose PBMCs were as follows: (1) at present, there is no relevant research on WISP1 methylation in PBMCs; and (2) PBMCs can easily be obtained from participants' peripheral blood by noninvasive methods. The aim of our study was to find a noninvasive biomarker for distinguishing patients with HCC from patients with $\mathrm{CHB}$, so it is important to expediently obtain research samples from the clinic.

\section{Materials and Methods}

\section{Subjects}

A total of 123 participants with HBV infection-associated HCC, 90 patients with CHB and 38 healthy controls were enrolled in this study from the Department of Hepatology, Qilu Hospital of Shandong University, from June 2018 to September 2019. Patients with HCC were recruited according to the 2010 update of the American Association for the Study of Liver Diseases (AASLD) Practice Guidelines for Management of HCC. Patients with CHB were diagnosed based on the presence of the hepatitis B surface antigen ( $\mathrm{HBsAg}$ ) for at least 6 months. All patients with the following situations were excluded: coinfection with other viruses or other hepatitis, other liver diseases, history of other cancers, pregnancy, or metabolic disorders. This research was approved by the Medical Ethical Committee of Qilu Hospital of Shandong University and followed the Declaration of Helsinki guidelines. Written informed consent was obtained from all participants before collecting blood samples. The patient selection process is shown in Fig. 1. The basic characteristics of the subjects on the first day of hospital admission are shown in Table 1.

\section{DNA extraction from PBMCs and sodium bisulfite modification}

Blood samples were collected after the participants had fasted for 12 hours. Five milliliters of peripheral venous blood was drawn and placed in an anticoagulant tube. Plasma was obtained from the blood samples by centrifugation and stored at $-80^{\circ} \mathrm{C}$. PBMCs were isolated by gradient centrifugation in Ficoll-Paque (Pharmacia Diagnostics, Uppsala, Sweden). Genomic DNA was extracted from PBMCs using the QIAamp DNA Blood Mini Kit (Qiagen, Hilden, Germany) following the standard protocol and was stored at $-20^{\circ} \mathrm{C}$ for bisulfite conversion. The concentration and purity of the extracted DNA were measured using an Eppendorf Biophotometer (Brinkmann Instruments, Westbury, NY). Bisulfite conversion was performed using the EZ DNA Methylation-Gold Kit (Zymo Research Corp, Orange, CA). Finally, $20 \mu \mathrm{l}$ of modified DNA was acquired for MSP. 


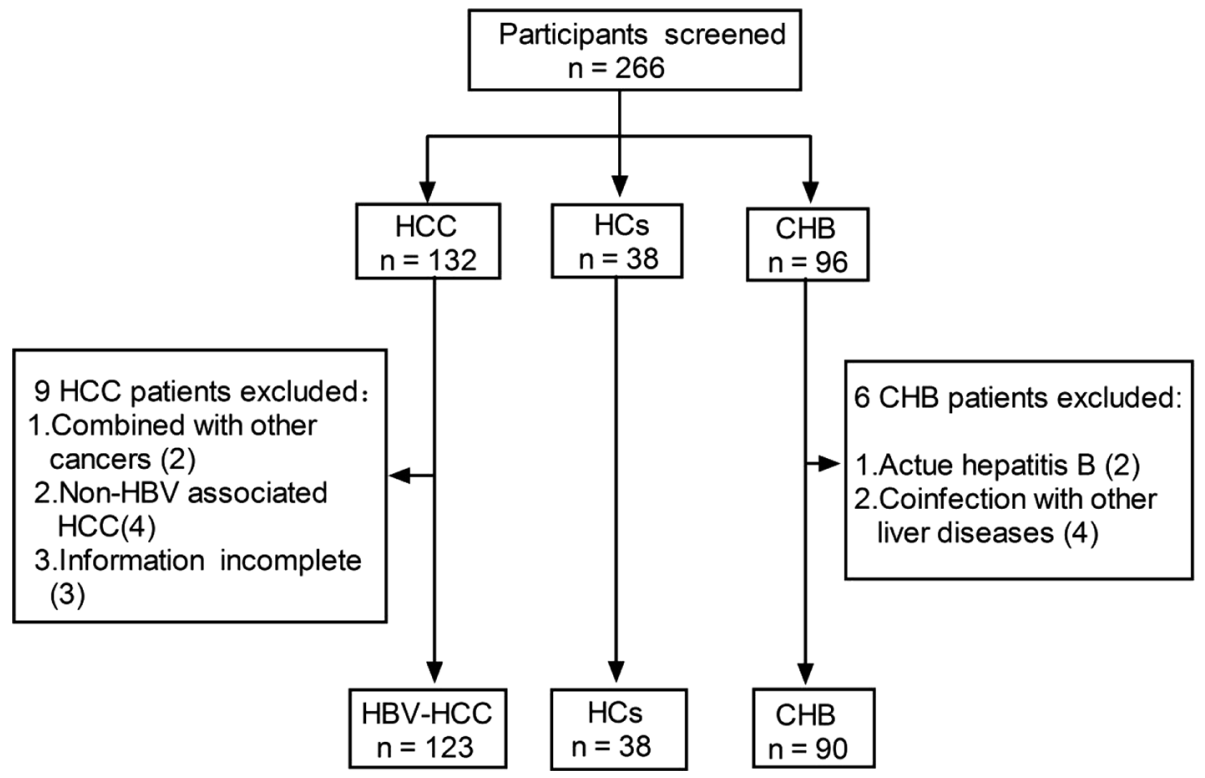

Fig. 1. The selection of participants.

Table 1. Clinical characteristics of enrolled participants.

\begin{tabular}{|c|c|c|c|c|}
\hline Variables & $\mathrm{HCC}(\mathrm{n}=123)$ & $\mathrm{CHB}(\mathrm{n}=90)$ & $\operatorname{HCs}(\mathrm{n}=38)$ & $\mathrm{p}$ value \\
\hline Age (years) & $50.00(45.00-56.00)$ & $49.00(37.50-54)$ & $48.00(46.00-57.25)$ & $0.110^{\circ}$ \\
\hline $\operatorname{Sex}(M / F)$ & $98 / 25$ & $64 / 26$ & $25 / 13$ & $0.150^{\mathrm{a}}$ \\
\hline HBsAg & $5,461.5(2,513.5-6,496.25)$ & $5,851(2,956-6,721)$ & NA & $0.433^{b}$ \\
\hline $\operatorname{HBeAg}(-/+)$ & $87 / 36$ & $33 / 57$ & NA & $<0.001^{\mathrm{a}}$ \\
\hline HBV DNA $(-/+)$ & $53 / 70$ & $30 / 60$ & NA & $0.149^{\mathrm{a}}$ \\
\hline $\operatorname{ALT}(\mathrm{U} / \mathrm{I})$ & $64(51-92.25)$ & $64(53.25-108.75)$ & $22.5(16.75-28)$ & $<0.001^{\mathrm{c}}$ \\
\hline $\operatorname{AST}(\mathrm{U} / \mathrm{I})$ & $71(59.25-110.25)$ & $74.5(62-113.5)$ & $20(16-27.75)$ & $<0.001^{\mathrm{c}}$ \\
\hline TBIL $(\mu \mathrm{mol} / \mathrm{L})$ & $22.1(13.98-39.38)$ & $24.7(15.08-56.95)$ & $9.45(7.3-12.23)$ & $<0.001^{\mathrm{c}}$ \\
\hline $\mathrm{TAB}(\mu \mathrm{mol} / \mathrm{L})$ & $25.2(11.7-55.4)$ & $32.1(12.5-63.8)$ & $7.75(4.98-10.1)$ & $<0.001^{\mathrm{c}}$ \\
\hline $\operatorname{ALB}(g / L)$ & $38.55(33.05-42.98)$ & $35.8(30.05-40.6)$ & $43.85(41.83-44.9)$ & $<0.001^{\mathrm{c}}$ \\
\hline INR & $1.18(1.1-1.28)$ & $1.34(1.16-1.64)$ & NA & $<0.001^{\mathrm{b}}$ \\
\hline PTA $(\%)$ & $78(70-85.75)$ & $65(50-80.5)$ & NA & $<0.001^{\mathrm{b}}$ \\
\hline $\mathrm{Cr}(\mu \mathrm{mol} / \mathrm{L})$ & $64(53-72)$ & $63(53.75-73.25)$ & $85.5(78-92.5)$ & $<0.001^{\mathrm{c}}$ \\
\hline $\operatorname{AFP}(\mathrm{ng} / \mathrm{ml})$ & $87.51(4.43-1,066.98)$ & $7.8(2.84-25.85)$ & NA & $<0.001^{\mathrm{b}}$ \\
\hline
\end{tabular}

Quantitative variables are expressed as the median (centile 25; centile 75).

Categorical variables are expressed as number (\%).

HCC, HBV-associated hepatocelluar carcinoma; CHB, chronic hepatitis B; HCs, healthy controls; HBsAg, hepatitis B surface antigen; $\mathrm{HBeAg}$, hepatitis e surface antigen; HBV, hepatitis B virus; ALT, alanine aminotransferase; AST, aspartate aminotransferase; TBIL, total bilirubin; TAB, total bile acids; ALB, albumin; INR, international normalized ratio; PTA, prothrombin time activity; Cr, creatinine; NA, not available.

${ }^{\mathrm{a} C h i}$-square test.

'Mann-Whitney $U$-test.

${ }^{\mathrm{c}}$ Kruskal-Wallis $\mathrm{H}$ test.

\section{Methylation-specific polymerase chain reaction (MSP)}

The reference promoter sequence for the human WISP1 gene was obtained from the UCSC human genome browser and Ensembl genome browser, which is the widely recognized public platform for searching gene promoter sequence (Kent et al. 2002; Aken et al. 2017; Chadaeva et al. 2019; Huang et al. 2019). The methylated (M) and unmethylated (U) WISP1 promoter-specific primers were designed by MethPrimer following its published standards (Li and Dahiya 2002). The amplified regions corresponding to the primers designed by MethPrimer were 621-793 (shown in Fig. 2a, b), and the expected product size was $173 \mathrm{bp}$. Primers for MSP of WISP1 were as follows: methylated forward primer: 5'-TTATTGTGGTT 


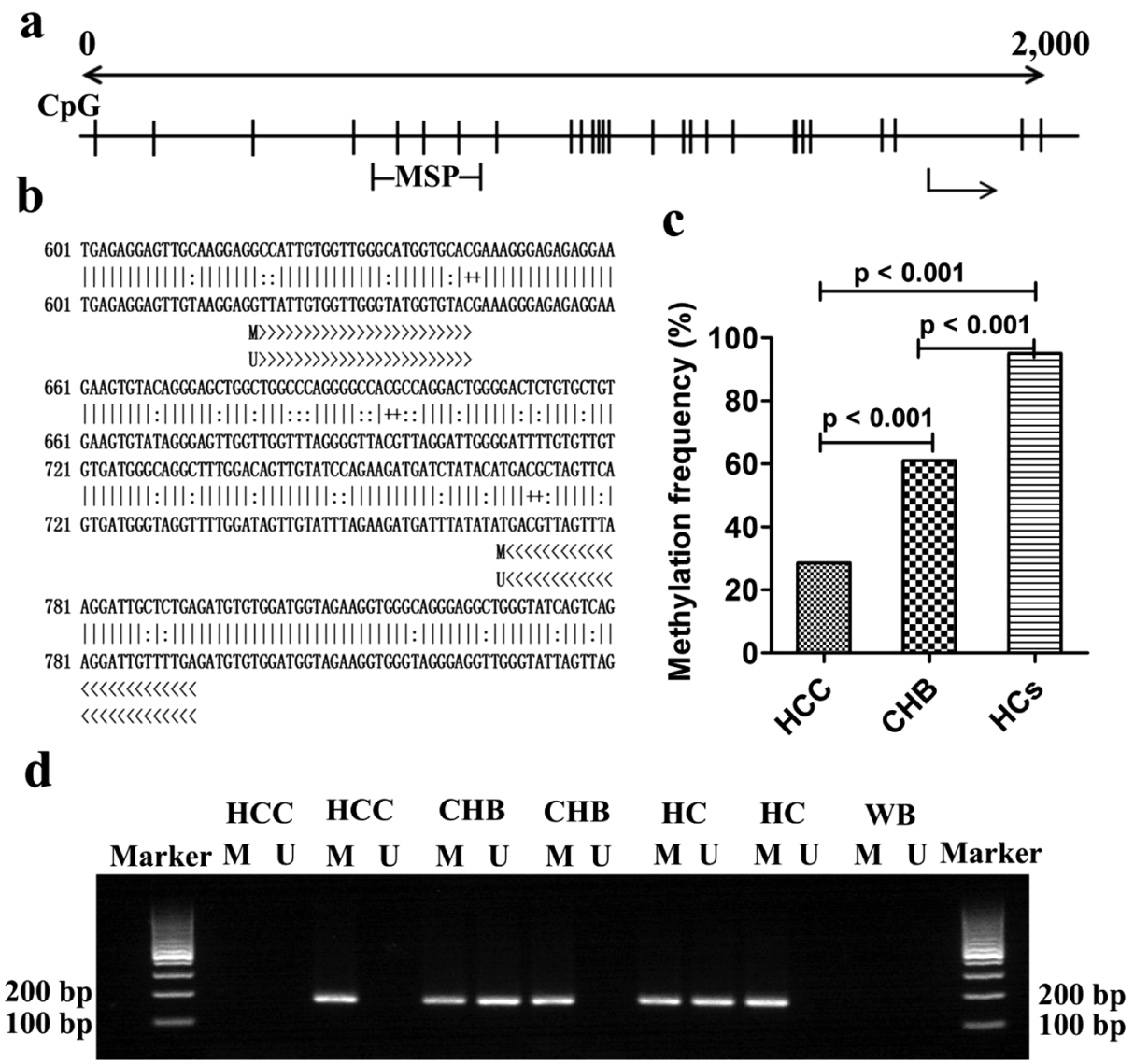

Fig. 2. Schematic representation of the WISPI gene and the level of WISP1 promoter methylation in PBMCs of participants.

(a) MSP-amplified regions (621-793) are indicated, and the transcription start site is indicated by a curved arrow.

(b) The amplified regions in WISP1 promoter sequence obtained from MethPrimer.

Upper row, Original sequence; Lower row, Bisulfite modified sequence; $M \gg \gg>>>$, methylated-specific forward primer; $\mathrm{M}<<<<<<$, methylated-specific reverse primer; $\mathrm{U}>>>>>>$, unmethylated-specific forward primer; $\mathrm{U}<<<<<<$, unmethylated-specific reverse primer; ++, $\mathrm{CpG}$ sites; ::.:., Non-CpG ' $\mathrm{C}$ ' converted to ' $\mathrm{T}$ '.

(c) Methylation frequency of WISPI in patients with HCC, patients with CHB and HCs.

(d) Typical image from MSP analysis of the WISP1 gene promoter.

$\mathrm{M}$, methylated sequence; U, unmethylated sequence; HCC, hepatocellular carcinoma; CHB, chronic hepatitis B; HC, healthy control; WB, water blank.

GGGTATGGTGTAC-3', methylated reverse primer: 5'-TCAAAACAATCCTTAAACTAACGTC-3', unmethylated forward primer: 5'-TTATTGTGGTTGGG TATGGTGTAT-3', unmethylated reverse primer: 5'-TCAAAAACAATCCTTAAACTAACATC-3'. The $25 \mu$ 1 total MSP reaction mixture included $1 \mu \mathrm{l}$ modified DNA, $0.5 \mu \mathrm{l}$ forward and reverse primers $(10 \mu \mathrm{M}), 12.5 \mu \mathrm{l}$ ZymoTaq $^{\mathrm{TM}}$ premix (Zymo Research Corp, CA, USA) and $10.5 \mu \mathrm{l}$ nuclease-free water. The conditions of MSP were as follows: initial denaturation at $95^{\circ} \mathrm{C}$ for 10 minutes; 40 cycles of denaturation at $94^{\circ} \mathrm{C}$ for 30 seconds, annealing at $59.5^{\circ} \mathrm{C}$ for 30 seconds, primer extension at $72^{\circ} \mathrm{C}$ for $30 \mathrm{sec}-$ onds, and final extension at $72^{\circ} \mathrm{C}$ for 10 minutes. DNAsefree water served as a negative control. Amplified PCR products were electrophoresed on $2 \%$ agarose gels, stained with GelRed (Biotium, CA) and visualized under UV illumination. Experiments were performed three times for each MSP.

\section{$R N A$ extraction from $P B M C s$ and $R T-q P C R$}

Total RNA was simultaneously extracted from PBMCs by TRIzol Reagent (Invitrogen). cDNA was synthesized from $20 \mu \mathrm{l}$ RNA by marking use of a first-strand cDNA synthesis kit (Fermentas, Vilnius, Lithuania). RT-qPCR to quantify WISP1 mRNA levels was conducted with SYBR Premix Ex Taq ${ }^{\mathrm{TM}}$ (Toyobo, Osaka, Japan) and an Agilent Technologies Stratagene Mx3005P instrument (Stratagene, La Jolla, CA), with $\beta$-actin as an internal control. The $10 \mu \mathrm{l}$ reaction mixture included $0.5 \mu \mathrm{l}$ of cDNA, $5 \mu \mathrm{l}$ of SYBR Green, $0.2 \mu \mathrm{l}$ of each primer, and $4.1 \mu \mathrm{l}$ of nuclease-free water. The RT-qPCR process was as follows: $95^{\circ} \mathrm{C}$ for 30 seconds, followed by 45 cycles of $95^{\circ} \mathrm{C}$ for 5 seconds, $60^{\circ} \mathrm{C}$ for 30 seconds, and $72^{\circ} \mathrm{C}$ for 30 seconds. The primers for WISP 1 and $\beta$-actin were the same as those previously used, and the sequences were as follows: WISP1 forward: 5'-TTATTGTGGTTGGGTATGGTGTAC-3'; WISP1 reverse: 5'-TCAAAACAATCCTTAAACTAACGTC-3'; $\beta$ - a c t in forward: $5^{\prime}$ - A T GGG TCA G A A 
G G A T T C C TATG T G-3'; $\beta$-actin reverse : 5'-CTTCATGAGGTAGTCAGTCAGGTC-3'. Each reaction was repeated three times. The mRNA levels were measured using the comparative $\left(2^{-\Delta \Delta \mathrm{Ct}}\right)$ method.

\section{ELISA for WISP1 in plasma}

The concentration of soluble WISP1 was detected in this study using the WISP1 ELISA Kit (Shanghai Lengton Bioscience, China) according to the instructions.

\section{Clinical parameter collection}

Clinical features included HBV DNA load, HBsAg, HBeAg, AFP, ALT, AST, total bilirubin (TBIL), total bile acids (TBA), albumin (ALB), prothrombin time activity (PTA), international standardization ratio (INR), and creatinine (Cr) levels, tumor size, tumor node metastasis (TNM) stage, Child-Turcotte-Pugh (CTP) classification (detailed standards of CTP class are presented in Table 2), and vascular invasion, which were obtained from the Department of Laboratory Medicine, Qilu Hospital of Shandong University.

\section{Statistical analysis}

The data analyses were performed using SPSS 21.0 (Chicago, IL, USA) and GraphPad Prism 5 (GraphPad Software Inc., San Diego, CA, USA). The KolmogorovSmirnov test was performed to determine whether the data were normally distributed. The percentage of methylated samples in all samples was the methylation frequency. The methods of quantitative variable analysis were the MannWhitney $U$-test and Kruskal-Wallis $\mathrm{H}$ test, and categorical variables were compared using the Chi-square test. Spearman's rank order correlation test was applied to evaluate the correlations between different variables. The receiver operating characteristic (ROC) curve and area under the curve (AUC) were used to assess the clinical value of methylation. A two-sided $p<0.05$ was considered statistically significant.

\section{Results}

\section{General characteristics of participants}

The demographic characteristics, clinical parameters and laboratory measurements of the included participants

Table 2. Child-Turcotte-Pugh (CTP).

\begin{tabular}{lccc}
\hline \multirow{2}{*}{ Clinical index } & \multicolumn{3}{c}{ Score } \\
\cline { 2 - 4 } & 1 & 2 & 3 \\
\hline Hepatic encephalopathy & no & $1-2$ & $3-4$ \\
Ascites & no & mild & severe \\
TBIL $(\mu \mathrm{mol} / \mathrm{L})$ & $<34$ & $34-51$ & $>51$ \\
ALB $(\mathrm{g} / \mathrm{L})$ & $>35$ & $28-35$ & $<28$ \\
INR & $<1.7$ & $1.7-2.3$ & $>2.3$ \\
\hline
\end{tabular}

Class A: score5-6; Class B:score 7-9; Class C: score 10-15. are shown in Table 1.

Methylation status of the WISP1 promoter in patients with $H C C$, patients with $C H B$ and $H C s$.

The methylation status of the WISP1 gene promoter in patients with $\mathrm{HCC}$, patients with $\mathrm{CHB}$ and $\mathrm{HCs}$ was detected by MSP. According to the results of agarose gel electrophoresis, if a band was present in the lane in which the MSP product of the methylated WISP1 promoter-specific primer was added, it represented that the WISP 1 promoter was methylated. The same was true for unmethylation products. There were 15 samples positive for both methylation- and unmethylation-specific PCR; we considered them to be a methylation-specific PCR-positive group due to the existence of WISP 1 promoter methylation. Thirty-five of 123 (28.5\%) patients with HCC showed WISP1 gene methylation, while 55 of $90(61.1 \%)$ patients with CHB and 36 of $38(94.7 \%)$ HCs exhibited WISP1 promoter methylation. The methylation frequency of patients with $\mathrm{HCC}$ was predominantly lower than that of patients with CHB $\left(\chi^{2}=22.714, p<0.001\right)$ and HCs $\left(\chi^{2}=51.737\right.$, p $<0.001$; Fig. 2c). A typical image from the MSP analysis of WISP1 is presented in Fig. $2 \mathrm{~d}$.

Correlation between WISP1 gene methylation status and clinicopathological parameters in HCC

Table 3 shows the association between the methylation status of the WISPI promoter and the clinical data of patients with HBV-associated HCC. The level of AFP was visibly higher in the unmethylated group than in the methylated group $(\mathrm{Z}=3.266, \mathrm{p}=0.001)$, and the methylation frequency in TNM stage I/II (36.6\%) was also significantly higher than that in TNM stage III/IV $\left(17.3 \%, \chi^{2}=5.49, \mathrm{p}=\right.$ 0.019). Meanwhile, the methylation frequency of tumor size $\geq 5 \mathrm{~cm}(16.7 \%)$ was clearly lower than that of tumor sizes $<5 \mathrm{~cm}\left(39.7 \%, \chi^{2}=7.99, \mathrm{p}=0.005\right)$. However, there were no obvious associations between the methylation status of the WISP 1 gene and age, sex, HBsAg, HBeAg, HBV DNA, ALT, AST, TBIL, TAB, ALB, INR, PTA, Cr, vascular invasion or Child-Turcotte-Pugh (CTP) class. Moreover, the multivariate logistic regression showed that sex and AFP affected WISP1 promoter methylation (Table 4).

WISP1 mRNA level in PBMCs of patients with HCC, patients with $C H B$ and $H C S$

WISP 1 mRNA levels were evidently upregulated in patients with HCC compared with those in patients with $\mathrm{CHB}$ and HCs. The mRNA level was significantly higher in patients with $\mathrm{HCC}$ than in patients with $\mathrm{CHB}(\mathrm{Z}=4.822$, $\mathrm{p}<0.001)$ and HCs $(Z=5.751, p<0.001)$. In addition, the mRNA level was also higher in the CHB group than in the $\mathrm{HC}$ group $(\mathrm{Z}=2.446, \mathrm{p}=0.043)$ (Fig. $3 \mathrm{a})$. In the $\mathrm{HCC}$ subgroup, WISP1 mRNA levels were distinctly lower in patients with methylation than in those without methylation $(\mathrm{Z}=4.613, \mathrm{p}<0.001)$ (Fig. 3b). Moreover, the mRNA level of WISPI was higher in patients with positive $\mathrm{HBeAg}$ 
Table 3. Correlation between WISP1 gene methylation status and clinicopathological parameters in HBV-associated HCC.

\begin{tabular}{|c|c|c|c|c|}
\hline \multirow{2}{*}{ Parameters } & \multicolumn{2}{|c|}{ WISP1 methylation status } & \multirow{2}{*}{ Statistics } & \multirow{2}{*}{$\mathrm{p}$ value } \\
\hline & Methylated $(\mathrm{n}=35)$ & Unmethylated $(\mathrm{n}=88)$ & & \\
\hline Age (years) & $51(45-58)$ & $50(44.75-55)$ & $Z=-0.700$ & $0.484^{\mathrm{b}}$ \\
\hline $\operatorname{Sex}(M / F)$ & $31 / 4$ & $67 / 21$ & $\chi^{2}=2.391$ & $0.122^{\mathrm{a}}$ \\
\hline HBsAg & $5,037(2,715.25-6,513)$ & $5,507(2,403-6,747)$ & $Z=0.318$ & $0.751^{b}$ \\
\hline $\operatorname{HBeAg}(+/-)$ & $10 / 25$ & $26 / 62$ & $\chi^{2}=0.011$ & $0.915^{\mathrm{a}}$ \\
\hline HBV DNA (+/-) & $16 / 19$ & $54 / 34$ & $\chi^{2}=2.501$ & $0.114^{\mathrm{a}}$ \\
\hline $\operatorname{ALT}(\mathrm{U} / \mathrm{I})$ & $64(52-91)$ & $64(51-98.5)$ & $Z=-0.569$ & $0.569^{\mathrm{b}}$ \\
\hline $\operatorname{AST}(\mathrm{U} / \mathrm{I})$ & $71(59-107.5)$ & $71(60-115.5)$ & $Z=-0.190$ & $0.850^{\mathrm{b}}$ \\
\hline TBIL $(\mu \mathrm{mol} / \mathrm{L})$ & $22.6(15.85-32.75)$ & $21.8(13.85-40.4)$ & $Z=-0.391$ & $0.696^{\mathrm{b}}$ \\
\hline $\mathrm{TAB}(\mu \mathrm{mol} / \mathrm{L})$ & $29.8(12.3-56)$ & $20.8(11.45-53.6)$ & $Z=-0.721$ & $0.471^{\mathrm{b}}$ \\
\hline $\operatorname{ALB}(\mathrm{g} / \mathrm{L})$ & $38.4(33.05-42.1)$ & $38.6(33.2-43.15)$ & $Z=0.422$ & $0.673^{\mathrm{b}}$ \\
\hline INR & $1.19(1.125-1.325)$ & $1.18(1.1-1.245)$ & $Z=-0.937$ & $0.349^{\mathrm{b}}$ \\
\hline PTA $(\%)$ & $76(65-83.5)$ & $78(71.5-86)$ & $Z=1.014$ & $0.311^{\mathrm{b}}$ \\
\hline $\mathrm{Cr}(\mu \mathrm{mol} / \mathrm{L})$ & $59(51.5-75)$ & $64(53.25-70.5)$ & $Z=0.392$ & $0.695^{\mathrm{b}}$ \\
\hline $\mathrm{AFP}(\mathrm{ng} / \mathrm{ml})$ & $7.98(3.33-83.2)$ & $212.6(11.53-2,151)$ & $Z=3.266$ & $0.001^{\mathrm{b}}$ \\
\hline Vascular invasion $(+/-)$ & $7 / 28$ & $32 / 56$ & $\chi^{2}=3.097$ & $0.078^{\mathrm{a}}$ \\
\hline CTP class & & & $\chi^{2}=0.462$ & $0.794^{\mathrm{a}}$ \\
\hline A & 24 & 55 & & \\
\hline B & 9 & 28 & & \\
\hline $\mathrm{C}$ & 2 & 5 & & \\
\hline Tumor size & & & $\chi^{2}=7.997$ & $0.005^{\mathrm{a}}$ \\
\hline$\geq 5 \mathrm{~cm}$ & $10(16.7 \%)$ & $50(83.3 \%)$ & & \\
\hline$<5 \mathrm{~cm}$ & $25(39.7 \%)$ & $38(60.3 \%)$ & & \\
\hline TNM stage & & & $\chi^{2}=5.499$ & $0.019^{\mathrm{a}}$ \\
\hline $\mathrm{I} / \mathrm{II}$ & $26(36.6 \%)$ & $45(63.4 \%)$ & & \\
\hline III/IV & $9(17.3 \%)$ & $43(82.7 \%)$ & & \\
\hline
\end{tabular}

TNM,Tumor node metastasis.

${ }^{a}$ Chi-square test.

'Mann-Whitney $U$-test.

Table 4. Multivariate logistic regression analysis of clinicopathological characteristics of the WISP1 promoter methylation in HCC.

\begin{tabular}{lcccc}
\hline Variables & Coefficient & OR & $95 \%$ CI & p value \\
\hline Age & 0.003 & 1.003 & $0.948-1.062$ & 0.907 \\
Sex & -2.049 & 0.129 & $0.037-0.447$ & 0.001 \\
AFP & 0.000 & 1.000 & $1.000-1.000$ & 0.048 \\
TBIL & -0.001 & 0.999 & $0.992-1.006$ & 0.803 \\
PTA & -0.023 & 0.977 & $0.938-1.018$ & 0.260 \\
Cr & 0.010 & 1.010 & $0.987-1.034$ & 0.380 \\
HBsAg & 0.000 & 1.000 & $1.000-1.000$ & 0.645 \\
ALB & -0.071 & 0.931 & $0.839-1.033$ & 0.178 \\
Size & -0.943 & 0.390 & $0.134-1.134$ & 0.084 \\
TNM stage & 0.321 & 1.379 & $0.492-3.863$ & 0.541 \\
\hline
\end{tabular}

than in those with negative $\mathrm{HBeAg}(\mathrm{Z}=2.185, \mathrm{p}=0.029)$ (Fig. 3c). However, no evident discrepancies were found between the mRNA levels of WISP1 and HBV DNA, HBsAg, TNM stage, tumor size, vascular invasion or other parameters.
Expression of plasma WISP1 in patients with HCC, patients with $\mathrm{CHB}$ and $\mathrm{HCs}$

The level of plasma WISP1 was detected by ELISA. We found that the concentration of WISP1 was significantly decreased in patients with $\mathrm{HCC}(1.543 \pm 0.731 \mu \mathrm{g} / \mathrm{L}) \mathrm{com}-$ 

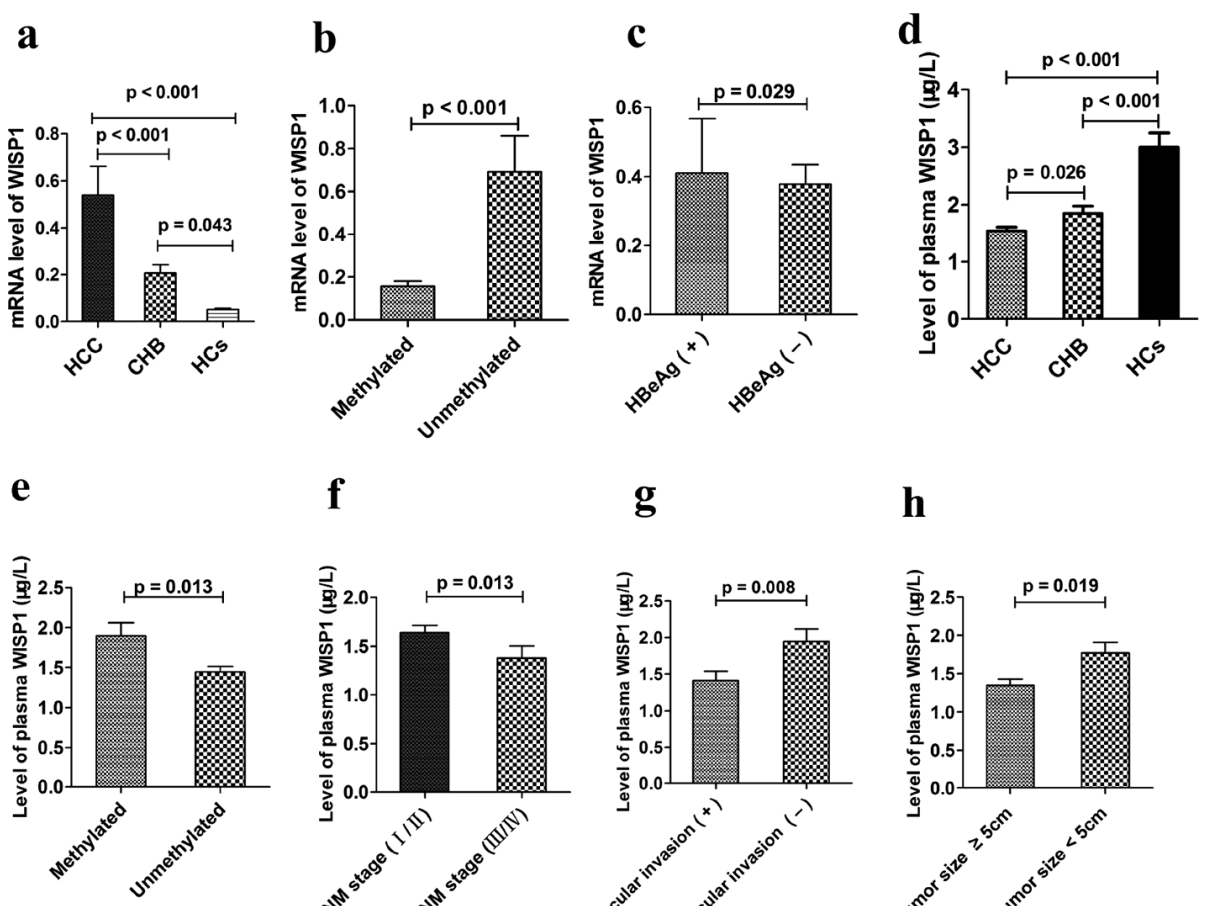

f
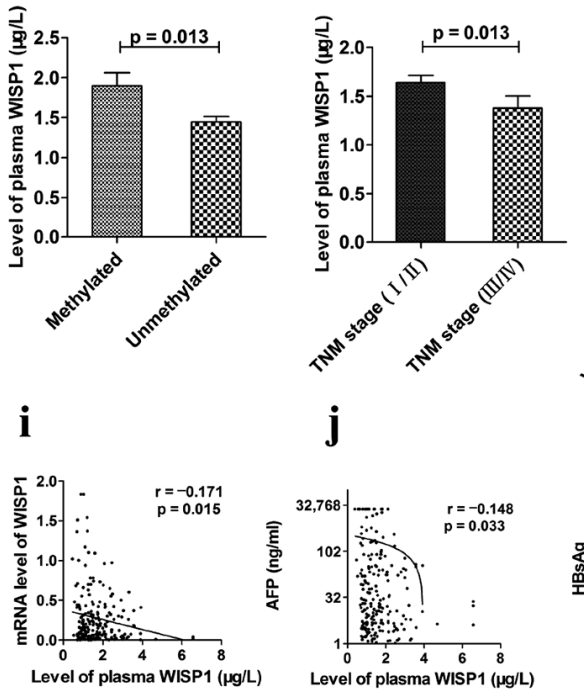

g

$\mathbf{h}$
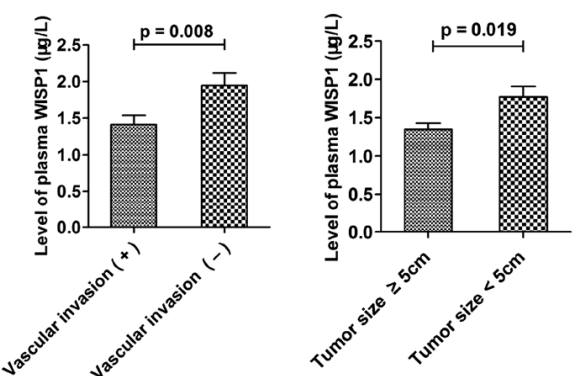

\section{$\mathbf{k}$}
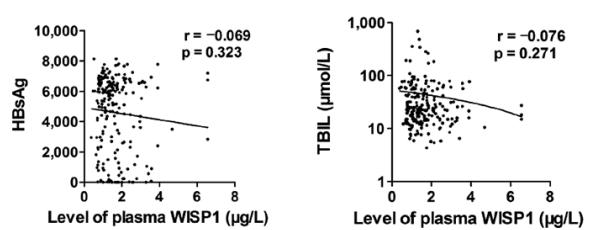

Fig. 3. Association of WIPS1 expression with clinical parameters.

(a) mRNA level of WISPI in PBMCs of patients with HCC, patients with CHB and HCs.

(b) The mRNA level of WISP1 is lower in HCC with methylation than unmethylation $(\mathrm{Z}=4.613, \mathrm{p}<0.001)$.

(c) mRNA expression was higher in the $\mathrm{HBeAg}(+)$ group than in the $\mathrm{HBeAg}(-)$ group $(\mathrm{Z}=2.185, \mathrm{p}=0.029)$.

(d) Level of plasma WISP1 in patients with HCC, patients with CHB and HCs.

(e) The level of plasma WISP1 was higher in the methylated group than in the unmethylated group $(\mathrm{Z}=-2.486, \mathrm{p}=$ $0.013)$.

(f-h) The plasma WISP1 concentration showed significance with TNM stage $(Z=-2.493, p=0.013)$, vascular invasion $(Z$ $=2.666, \mathrm{p}=0.008)$, and tumor size $(\mathrm{Z}=2.340, \mathrm{p}=0.019)$.

(i) The correlation between WISP1 mRNA and plasma WISP1 expression $(\mathrm{r}=-0.171, \mathrm{p}=0.015)$.

(j) Plasma WISP1 levels showed a significant negative correlation with AFP levels $(\mathrm{r}=-0.148, \mathrm{p}=0.033)$.

(k-l) There were no significant correlations between the plasma levels of WISP1 and HBsAg or TBIL.

pared with that in patients with CHB $(1.852 \pm 1.188 \mu \mathrm{g} / \mathrm{L}, \mathrm{p}$ $=0.026)$ and $\mathrm{HCs}(3.001 \pm 1.269 \mu \mathrm{g} / \mathrm{L}, \mathrm{p}<0.001)$, and the difference between them was statistically significant (Fig. 3d). The level of WISP1 was visibly higher in the methylation group than in the unmethylation group $(Z=-2.486, p=$ 0.013 ) (Fig. 3e). Simultaneously, plasma WISP1 was significantly associated with TNM stage $(Z=-2.493, \mathrm{p}=$ $0.013)$, vascular invasion $(Z=2.666, p=0.008)$, and tumor size $(Z=2.340, p=0.019)$ (Fig. 3f-h). We observed that the level of plasma WISP1 disaccorded mRNA expression, and the plasma WISP1 concentration was negatively correlated with WISP1 mRNA expression $(\mathrm{r}=-0.171, \mathrm{p}=0.015)$ (Fig. 3i). Therefore, we inferred that there was a correlation between mRNA expression and plasma WISP1 protein.
In addition, plasma WISP1 levels showed a significant negative correlation with AFP levels $(\mathrm{r}=-0.148, \mathrm{p}=0.033)$ (Fig. 3j). No significant relationships were detected with HBsAg (Fig. 3k), TBIL (Fig. 31), ALT, AST, ALB, INR, PTA and Cr levels.

Diagnostic value of AFP level and WISP1 methylation in HCC

ROC curves were constructed to estimate the performance of WISP1 promoter methylation and AFP as biomarkers for discriminating patients with $\mathrm{HBV}$-associated HCC from patients with CHB. Abnormal WISP1 gene methylation presented a sensitivity of $71.45 \%$ and specificity of $57.95 \%$ in distinguishing patients with HCC from 
patients with CHB, and AFP showed a sensitivity of $53.39 \%$ and specificity of $82.56 \%$. In addition, the combination of WISP1 methylation and serum AFP levels displayed a sensitivity of $71.19 \%$ and specificity of $67.44 \%$. The area under the receiver operating characteristic (ROC) curve (AUC) of WISP1 promoter methylation and AFP levels was 0.647 and 0.667 , respectively, and the AUC of the combined determination (0.736) was significantly higher than that of AFP $(\mathrm{Z}=2.207, \mathrm{p}=0.0273)$ or WISP1 gene methylation $(Z=2.797, p=0.0052)$ (Table 5, Fig. 4). The results suggested that the combination of WISP1 gene methylation and serum AFP levels might be an optimal biomarker for the distinction of patients with $\mathrm{HBV}$-associated $\mathrm{HCC}$ from patients with $\mathrm{CHB}$.

\section{Discussion}

In our study, we detected the methylation status of the WISP1 gene promoter in $123 \mathrm{HBV}$-associated HCC

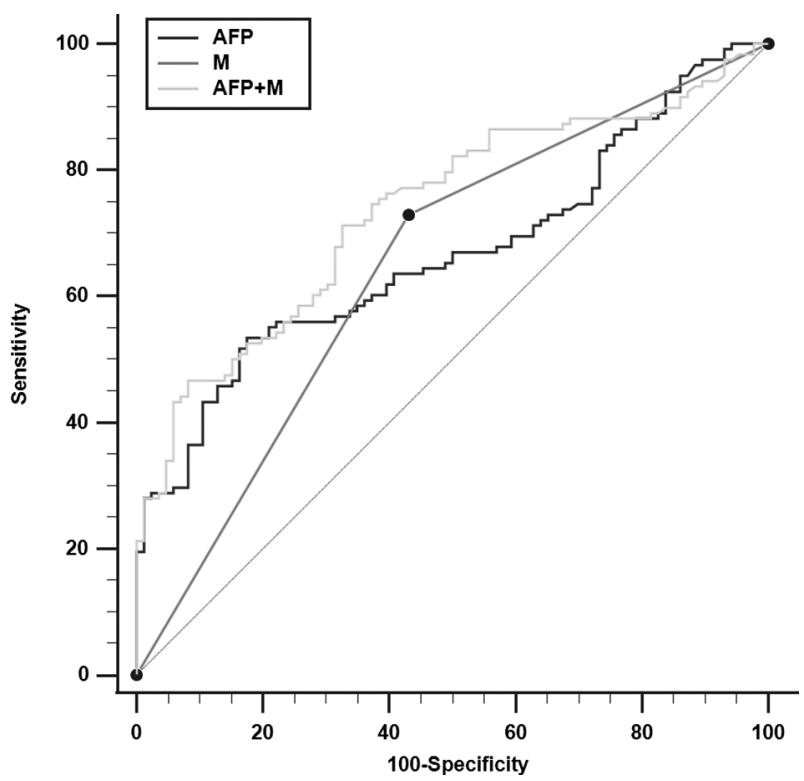

Fig. 4. Receiver operating characteristic curves of WISPI methylation and AFP level in distinguishing patients with HCC from patients with CHB.

AUC of WISP 1 methylation (AUC 0.649; 95\% CI: 0.580-0.715) and AUC of AFP level (AUC: $0.667 ; 95 \%$ CI: 0.598-0.732) were apparently lower than AUC for combination of the two biomarkers (AUC: $0.736 ; 95 \%$ CI: 0.670-0.796).

AUC, Area under the receiver operating characteristic curve; M, WISP1 methylation; AFP+M, AFP level combination WISP1 methylation. patients, $90 \mathrm{CHB}$ patients and $38 \mathrm{HCs}$. To the best of our knowledge, we first demonstrated that the methylation status of the WISP1 gene promoter in PBMCs was predominantly lower in patients with HBV-associated HCC than in patients with $\mathrm{CHB}$ and HCs. In addition, the mRNA expression of WISP1 was markedly increased in patients with HCC compared with patients with CHB and HCs. Therefore, hypomethylation of the WISPI gene promoter might contribute to the generation of chromosomal instability and improve mRNA expression. Furthermore, plasma soluble WISP1 expression was significantly decreased in patients with HCC compared with patients with $\mathrm{CHB}$ and HCs. Above all, the combination of the methylation status of the WISP 1 gene promoter in PBMCs and the serum AFP level visibly increased the AUC, suggesting that the combination of the two biomarkers will boost the distinction of HBV-associated HCC patients from CHB patients. Our results suggest that WISP1 may be a potential new diagnostic biomarker for distinguishing patients with HBVassociated HCC from patients with CHB.

Aberrant DNA methylation advances the occurrence and development of tumors (Esteller 2007). Cancer develops through the accumulation of genetic and epigenetic aberrations, and epigenetic changes are strongly associated with the development of HCC. As reported, many genes such as ADRAIA, ACADS, UBE2Q1, and ZCCH13 have been found to have aberrant methylation status in $\mathrm{HCC}(\mathrm{Hu}$ et al. 2017; Chen et al. 2019; Li et al. 2019; Chen et al. 2020). Abnormal methylation of genes may be promising biomarkers to timely and accurately distinguish patients with HBV-associated HCC from patients with CHB.

Wnt1-inducible signaling pathway protein 1 (WISP1) is a secreted, matricellular protein allocated to the $\mathrm{CCN}$ protein family. The $\mathrm{CCN}$ protein family consists of six modular structured secreted proteins. Soluble WISP1 is mainly expressed in epithelial and mesenchymal cells during organ development and under diseased conditions, such as fibrosis or cancer. Its expression is associated with proliferation, cytoprotection, and extracellular matrix production (Berschneider and Königshoff 2011). Abnormal WISP1 expression plays an important role in tumorigenesis and progression, and it has been confirmed in some solid tumors (Gaudreau et al. 2019), such as colon cancer, oral squamous cell carcinoma, and breast cancer (Chiang et al. 2015; Clausen et al. 2016; Wu et al. 2016). The role of WISP1 in tumors is controversial. WISP1 is the downstream target protein of $\beta$-catenin, which is active in tumors, and several articles implied that WISP1 was highly

Table 5. Diagnostic value of AFP and WISP1 methylation status in predicting HCC.

\begin{tabular}{lccccc}
\hline Parameter & $95 \%$ CI & Sensitivity (\%) & Specificity (\%) & Youden index & AUC \\
\hline AFP & $0.598-0.732$ & 53.39 & 82.56 & 0.3595 & 0.667 \\
M & $0.579-0.712$ & 71.54 & 57.95 & 0.2950 & 0.647 \\
AFP+M & $0.670-0.796$ & 71.19 & 67.44 & 0.3863 & 0.736 \\
\hline
\end{tabular}


expressed in tumors and regarded WISP1 as an oncogene (Xu et al. 2000; Deng et al. 2019; Jia et al. 2019; Zhang et al. 2019; Zheng et al. 2020). Some studies also suggested that WISP1 protein expression was low and acted as a tumor suppressor in some cancers (Shao et al. 2011; Tao et al. 2020). We explored the relationship of the methylation status of WISPI with the mRNA expression in PBMCs, and we came to the same conclusion as some studies that the mRNA expression of WISP 1 was significantly upregulated in HCC. However, the protein of WISP1 in plasma detected by ELISA was inconsistent with mRNA expression, and this is different from the results of some articles. The possible reasons for discordance of mRNA expression and plasma WISP1 protein are as follows: (1) protein posttranslational modification (PTM), which regulates many biological processes, can lead to discordant protein expression and mRNA expression. Yan et al. (2018) reported that human leukocyte antigen F adjacent transcript 10 (FAT10), a ubiquitin-like protein (UBL), promoted the expression of WISP 1 mRNA by stabilizing $\beta$-catenin, and FAT10 simultaneously exerted its degradation of WISP1 protein, which caused WISP1 protein and mRNA expression discordance. (2) The expression of mRNA is regulated by many factors, such as miRNA. (3) The protein WISP1 levels in plasma and cancer tissue may be different. Other studies tested samples of cancer tissue, but our tested samples were plasma.

Moreover, plasma WISP1 expression was notably reduced in the HCC group. Our data implied that plasma WISP1 concentration was correlated with TNM stage, vascular invasion and tumor size in HCC patients. We observed that plasma WISP1 levels were markedly lower in patients who were in advanced stage (TNM III/IV), had vascular invasion $(+)$ and had a tumor size $>5 \mathrm{~cm}$. The most important predictors of progression of HCC patients are tumor size, number of tumor nodules, tumor differentiation, and vascular invasion (Thuluvath 2009). Thus, we speculated that plasma WISP1 level might be a promising biomarker to predict the progress and prognosis of HBVassociated HCC. Moreover, the detection of plasma WISP1 by ELISA is easy to perform in clinical practice. However, whether the plasma WISP1 can influence and predict the prognosis of HCC still needs long-term follow-up and further validation.

AFP is a widely recognized biomarker to diagnose $\mathrm{HCC}$, and a previous study demonstrated that a cutoff value of $20 \mathrm{ng} / \mathrm{ml}$ had an optimal balance between sensitivity and specificity (Trevisani et al. 2001). Detecting serum AFP alone to distinguish patients with $\mathrm{HBV}$-associated $\mathrm{HCC}$ from patients CHB lacks enough sensitivity and specificity. It is vital to distinguish HCC patients from CHB patients in an early stage in a timely manner. In our study, we found that the combination of serum AFP level and the methylation status of WISP1 significantly enhanced the diagnostic value of individual biomarkers for distinguishing patients with HBV-associated HCC from patients with CHB. Thus, it is reasonable to believe that abnormal methylation of
WISP 1 might be a noninvasive biomarker to diagnose HCC.

There are several limitations in this study. (1) The number of subjects in our study was relatively small, and all came from a single center. A multicenter cohort and a long-term follow-up are needed. (2) The MSP we used for detecting the methylation status of the WISP1 promoter is quick and convenient, but it is only a qualitative measurement and might produce false-positive or false-negative results. Other quantitative approaches, such as gene sequencing, would be more beneficial in future research. (3) We estimated the methylated characters in PBMCs, and the intrahepatic methylation status was still unclear. We will detect WISP1 methylation and relative expression in liver tissue in the future. In conclusion, we first discovered hypomethylation of the WISPI gene promoter in HCC. In addition, WISPI promoter methylation may become a promising biomarker for the diagnosis of $\mathrm{HCC}$.

\section{Acknowledgments}

This work was supported by the Key Project of Chinese Ministry of Science and Technology (2017ZX102022022 and 2018ZX10302206), the National Natural Science Foundation of China (81970522), the Key Research and Development Project of Shandong Province (2019GSF108023), Shandong University multidisciplinary research and innovation team of young scholars (2020QNQT11).

\section{Conflict of Interest}

The authors declare no conflict of interest.

\section{References}

Aken, B.L., Achuthan, P., Akanni, W., Amode, M.R., Bernsdorff, F., Bhai, J., Billis, K., Carvalho-Silva, D., Cummins, C., Clapham, P., Gil, L., Giron, C.G., Gordon, L., Hourlier, T., Hunt, S.E., et al. (2017) Ensembl 2017. Nucleic Acids Res., 45, D635-D642.

Baubec, T. \& Schübeler, D. (2014) Genomic patterns and context specific interpretation of DNA methylation. Curr. Opin. Genet. Dev., 25, 85-92.

Berschneider, B. \& Königshoff, M. (2011) WNT1 inducible signaling pathway protein 1 (WISP1): a novel mediator linking development and disease. Int. J. Biochem. Cell Biol., 43, 306-309.

Bird, A. (2002) DNA methylation patterns and epigenetic memory. Genes Dev., 16, 6-21.

Bray, F., Ferlay, J., Soerjomataram, I., Siegel, R.L., Torre, L.A. \& Jemal, A. (2018) Global cancer statistics 2018: GLOBOCAN estimates of incidence and mortality worldwide for 36 cancers in 185 countries. CA Cancer J. Clin., 68, 394-424.

Byam, J., Renz, J. \& Millis, J.M. (2013) Liver transplantation for hepatocellular carcinoma. Hepatobiliary Surg. Nutr., 2, 22-30.

Chadaeva, I., Ponomarenko, P., Rasskazov, D., Sharypova, E., Kashina, E., Kleshchev, M., Ponomarenko, M., Naumenko, V., Savinkova, L., Kolchanov, N., Osadchuk, L. \& Osadchuk, A. (2019) Natural selection equally supports the human tendencies in subordination and domination: a genome-wide study with in silico confirmation and in vivo validation in Mice. Front. Genet., 10, 73.

Chen, D., Feng, X., Lv, Z., Xu, X., Lu, Y., Wu, W., Wu, H., Liu, H., Cao, L., Ye, S., Chen, J. \& Wu, J. (2019) ACADS acts as a 
potential methylation biomarker associated with the proliferation and metastasis of hepatocellular carcinomas. Aging (Albany NY), 11, 8825-8844.

Chen, G., Fan, X., Li, Y., He, L., Wang, S., Dai, Y., Bin, C., Zhou, D. \& Lin, H. (2020) Promoter aberrant methylation status of ADRA1A is associated with hepatocellular carcinoma. Epigenetics, 15, 684-701.

Chiang, K.C., Yeh, C.N., Chung, L.C., Feng, T.H., Sun, C.C., Chen, M.F., Jan, Y.Y., Yeh, T.S., Chen, S.C. \& Juang, H.H. (2015) WNT-1 inducible signaling pathway protein-1 enhances growth and tumorigenesis in human breast cancer. Sci. Rep., 5, 8686.

Chonprasertsuk, S. \& Vilaichone, R.K. (2017) Epidemiology and treatment of hepatocellular carcinoma in Thailand. Jpn. J. Clin. Oncol., 47, 294-297.

Clausen, M.J., Melchers, L.J., Mastik, M.F., Slagter-Menkema, L., Groen, H.J., van der Laan, B.F., van Criekinge, W., de Meyer, T., Denil, S., Wisman, G.B., Roodenburg, J.L. \& Schuuring, E. (2016) Identification and validation of WISP1 as an epigenetic regulator of metastasis in oral squamous cell carcinoma. Genes Chromosomes Cancer, 55, 45-59.

Deng, W., Fernandez, A., McLaughlin, S.L. \& Klinke, D.J. 2nd (2019) WNT1-inducible signaling pathway protein 1 (WISP1/ CCN4) stimulates melanoma invasion and metastasis by promoting the epithelial-mesenchymal transition. J. Biol. Chem., 294, 5261-5280

Ding, X., He, M., Chan, A.W.H., Song, Q.X., Sze, S.C., Chen, H., Man, M.K.H., Man, K., Chan, S.L., Lai, P.B.S., Wang, X. \& Wong, N. (2019) Genomic and epigenomic features of primary and recurrent hepatocellular carcinomas. Gastroenterology, 157, 1630-1645 e1636.

Esteller, M. (2007) Epigenetic gene silencing in cancer: the DNA hypermethylome. Hum. Mol. Genet., 16 Spec No. 1, R50-59.

Ferlay, J., Colombet, M., Soerjomataram, I., Mathers, C., Parkin, D.M., Pineros, M., Znaor, A. \& Bray, F. (2019) Estimating the global cancer incidence and mortality in 2018: GLOBOCAN sources and methods. Int. J. Cancer, 144, 1941-1953.

Gaudreau, P.O., Clairefond, S., Class, C.A., Boulay, P.L., Chrobak, P., Allard, B., Azzi, F., Pommey, S., Do, K.A., Saad, F., Trudel, D., Young, M. \& Stagg, J. (2019) WISP1 is associated to advanced disease, EMT and an inflamed tumor microenvironment in multiple solid tumors. Oncoimmunology, 8, e1581545.

Ginno, P.A., Gaidatzis, D., Feldmann, A., Hoerner, L., Imanci, D., Burger, L., Zilbermann, F., Peters, A., Edenhofer, F., Smallwood, S.A., Krebs, A.R. \& Schubeler, D. (2020) A genomescale map of DNA methylation turnover identifies site-specific dependencies of DNMT and TET activity. Nat. Commun., 11, 2680.

Gurbuz, I. \& Chiquet-Ehrismann, R. (2015) CCN4/WISP1 (WNT1 inducible signaling pathway protein 1): a focus on its role in cancer. Int. J. Biochem. Cell Biol., 62, 142-146.

Hu, N., Fan, X.P., Fan, Y.C., Chen, L.Y., Qiao, C.Y., Han, L.Y. \& Wang, K. (2017) Hypomethylated ubiquitin-conjugating enzyme2 Q1 (UBE2Q1) gene promoter in the serum is a promising biomarker for hepatitis B virus-associated hepatocellular carcinoma. Tohoku J. Exp. Med., 242, 93-100.

Huang, S., Li, R., Huang, X., Zheng, S., Wang, L., Wen, Z., Zou, X., Wu, J., Liu, Y., Liu, D., Wang, Y., Dong, S., Chen, X., Zhu, K., Du, X., et al. (2019) Association study between methylation in the promoter regions of cGAS, MAVS, and TRAF3 genes and the risk of cervical precancerous lesions and cervical cancer in a Southern Chinese population. Front. Genet., 10, 1123.

Jaenisch, R. \& Bird, A. (2003) Epigenetic regulation of gene expression: how the genome integrates intrinsic and environmental signals. Nat. Genet., 33 Suppl, 245-254.

Jia, H., Janjanam, J., Wu, S.C., Wang, R., Pano, G., Celestine, M., Martinot, O., Breeze-Jones, H., Clayton, G., Garcin, C., Shiri- nifard, A., Zaske, A.M., Finkelstein, D. \& Labelle, M. (2019) The tumor cell-secreted matricellular protein WISP1 drives pro-metastatic collagen linearization. EMBO J., 38, e101302.

Kent, W.J., Sugnet, C.W., Furey, T.S., Roskin, K.M., Pringle, T.H., Zahler, A.M. \& Haussler, D. (2002) The human genome browser at UCSC. Genome Res., 12, 996-1006.

Kim, M. \& Costello, J. (2017) DNA methylation: an epigenetic mark of cellular memory. Exp. Mol. Med., 49, e322.

Lai, C.L., Ratziu, V., Yuen, M.F. \& Poynard, T. (2003) Viral hepatitis B. Lancet, 362, 2089-2094.

Lambert, M.P., Paliwal, A., Vaissière, T., Chemin, I., Zoulim, F., Tommasino, M., Hainaut, P., Sylla, B., Scoazec, J.Y., Tost, J. \& Herceg, Z. (2011) Aberrant DNA methylation distinguishes hepatocellular carcinoma associated with $\mathrm{HBV}$ and HCV infection and alcohol intake. J. Hepatol., 54, 705-715.

Li, J., Ye, L., Owen, S., Weeks, H.P., Zhang, Z. \& Jiang, W.G. (2015) Emerging role of CCN family proteins in tumorigenesis and cancer metastasis (Review). Int. J. Mol. Med., 36, 1451-1463.

Li, L.C. \& Dahiya, R. (2002) MethPrimer: designing primers for methylation PCRs. Bioinformatics, 18, 1427-1431.

Li, Z., Li, Z., Wang, L., Long, C., Zheng, Z. \& Zhuang, X. (2019) ZCCHC13-mediated induction of human liver cancer is associated with the modulation of DNA methylation and the AKT/ ERK signaling pathway. J. Transl. Med., 17, 108.

Liu, Y., Song, Y., Ye, M., Hu, X., Wang, Z.P. \& Zhu, X. (2019) The emerging role of WISP proteins in tumorigenesis and cancer therapy. J. Transl. Med., 17, 28.

Loftus, A., Cappariello, A., George, C., Ucci, A., Shefferd, K., Green, A., Paone, R., Ponzetti, M., Delle Monache, S., Muraca, M., Teti, A. \& Rucci, N. (2020) Extracellular vesicles from osteotropic breast cancer cells affect bone resident cells. J. Bone Miner. Res., 35, 396-412.

Luo, P., Wu, S., Yu, Y., Ming, X., Li, S., Zuo, X. \& Tu, J. (2020) Current status and perspective biomarkers in AFP negative HCC: towards screening for and diagnosing hepatocellular carcinoma at an earlier stage. Pathol. Oncol. Res., 26, 599-603.

Nagai, Y., Watanabe, M., Ishikawa, S., Karashima, R., Kurashige, J., Iwagami, S., Iwatsuki, M., Baba, Y., Imamura, Y., Hayashi, N. \& Baba, H. (2011) Clinical significance of Wnt-induced secreted protein-1 (WISP-1/CCN4) in esophageal squamous cell carcinoma. Anticancer Res., 31, 991-997.

Omata, M., Cheng, A.L., Kokudo, N., Kudo, M., Lee, J.M., Jia, J., Tateishi, R., Han, K.H., Chawla, Y.K., Shiina, S., Jafri, W., Payawal, D.A., Ohki, T., Ogasawara, S., Chen, P.J., et al. (2017) Asia-Pacific clinical practice guidelines on the management of hepatocellular carcinoma: a 2017 update. Hepatol. Int., 11, 317-370.

Ono, M., Inkson, C.A., Sonn, R., Kilts, T.M., de Castro, L.F., Maeda, A., Fisher, L.W., Robey, P.G., Berendsen, A.D., Li, L., McCartney-Francis, N., Brown, A.C., Crawford, N.P., Molinolo, A., Jain, A., et al. (2013) WISP1/CCN4: a potential target for inhibiting prostate cancer growth and spread to bone. PLoS One, $\mathbf{8}, \mathrm{e} 71709$.

Pennica, D., Swanson, T.A., Welsh, J.W., Roy, M.A., Lawrence, D.A., Lee, J., Brush, J., Taneyhill, L.A., Deuel, B., Lew, M., Watanabe, C., Cohen, R.L., Melhem, M.F., Finley, G.G., Quirke, P., et al. (1998) WISP genes are members of the connective tissue growth factor family that are up-regulated in wnt-1-transformed cells and aberrantly expressed in human colon tumors. Proc. Natl. Acad. Sci. USA, 95, 14717-14722.

Shao, H., Cai, L., Grichnik, J.M., Livingstone, A.S., Velazquez, O.C. \& Liu, Z.J. (2011) Activation of Notch1 signaling in stromal fibroblasts inhibits melanoma growth by upregulating WISP-1. Oncogene, 30, 4316-4326.

Smith, Z.D. \& Meissner, A. (2013) DNA methylation: roles in mammalian development. Nat. Rev. Genet, 14, 204-220.

Tao, W., Chu, C., Zhou, W., Huang, Z., Zhai, K., Fang, X., Huang, 
Q., Zhang, A., Wang, X., Yu, X., Huang, H., Wu, Q., Sloan, A.E., Yu, J.S., Li, X., et al. (2020) Dual Role of WISP1 in maintaining glioma stem cells and tumor-supportive macrophages in glioblastoma. Nat. Commun., 11, 3015.

Thuluvath, P.J. (2009) Vascular invasion is the most important predictor of survival in HCC, but how do we find it? J. Clin. Gastroenterol., 43, 101-102.

Trevisani, F., D’Intino, P.E., Morselli-Labate, A.M., Mazzella, G., Accogli, E., Caraceni, P., Domenicali, M., De Notariis, S., Roda, E. \& Bernardi, M. (2001) Serum alpha-fetoprotein for diagnosis of hepatocellular carcinoma in patients with chronic liver disease: influence of HBsAg and anti-HCV status. $J$. Hepatol., 34, 570-575.

Wu, J., Long, Z., Cai, H., Du, C., Liu, X., Yu, S. \& Wang, Y. (2016) High expression of WISP1 in colon cancer is associated with apoptosis, invasion and poor prognosis. Oncotarget, 7, 4983449847.

Xu, L., Corcoran, R.B., Welsh, J.W., Pennica, D. \& Levine, A.J.
(2000) WISP-1 is a Wnt-1- and beta-catenin-responsive oncogene. Genes Dev., 14, 585-595.

Yan, J., Lei, J., Chen, L., Deng, H., Dong, D., Jin, T., Liu, X., Yuan, R., Qiu, Y., Ge, J., Peng, X. \& Shao, J. (2018) Human leukocyte antigen $\mathrm{F}$ locus adjacent transcript 10 overexpression disturbs WISP1 protein and mRNA expression to promote hepatocellular carcinoma progression. Hepatology, 68, 22682284.

Zhang, L.H., Wang, Y., Fan, Q.Q., Liu, Y.K., Li, L.H., Qi, X.W., Mao, Y. \& Hua, D. (2019) Up-regulated Wnt1-inducible signaling pathway protein 1 correlates with poor prognosis and drug resistance by reducing DNA repair in gastric cancer. World J. Gastroenterol., 25, 5814-5825.

Zheng, Y., Chen, C.J., Lin, Z.Y., Li, J.X., Liu, J., Lin, F.J. \& Zhou, X. (2020) Circ_KATNAL1 regulates prostate cancer cell growth and invasiveness through the miR-145-3p/WISP1 pathway. Biochem. Cell Biol., 98, 396-404. 